\title{
SOME STATEMENTS AND WAYS OF SOLVING \\ DYNAMIC OPIIMIZATION PROBLEMS UNDER UNCERTAINTY
}

\author{
I.S.BeIyaev \\ Siberian Power Institute \\ Ac.Sc., Irkutsk, USSR
}

Very many optimization problems, as related with system development, have a dynamic character and they are to be solved under uncertainty when for the part of initial information the probable description is neither known exactly nor available at all.

As is known [I], under uncertainty by a formalized solution of the problem it is generally impossible to find a single optimal variant. one may get but several rational variants that are the best on diverse criteria (Wald, Laplace, Savage et al.). But the final choice among them is made by experts based on their experience and intuition. Methods for solving such problems are insufficiently elaborated and they are investigated at the Siberian Power Institute,Ac.Sc.[2,3 et al.].

Under uncertainty it is expedient to make final deciaions only for those actions (variants, objects, etc.) which are urgont and should be realised immediately. These actions concern usualiy the neareat time peried called further"the first step". The other part of the studied period (period of "afteraction") is to be taken for the account of the consequences of these immediate actions, but the final decisions of the systom development for this period can be made later.

At such a tatement the question of the variant formation way (trajectory) of system development for the period of "afteraction" is complex enough. Apparently, such variants have to correspond on the one hand to actions of "the first step" (the following system development depends upon the choice of immediate objects) and on the other hand to impending conditions of yatem dovelopment (later decisions are made upon concret situations). However taking int account that at making subsequent decision uncertainty of information is also arailable and the final choice i made by men (intuitively, informalized), it im impossible to foresee these decision and definitely select the variants of sytem development for the period of "afteraction". Therefore hore can be proposed diverse approximate ways [3]. Some possiblo tatement will be considered below. The economical effect in the montioned problem can be estimated by the functional:

$$
3=\sum_{t=1}^{T} 3_{t}\left(x_{t-1}, x_{t}, y_{t}\right)
$$

where: $\quad T=$ total number of time intervals ("nteps");

$$
y_{t}=\text { vector f indefinite variables that characterizea }
$$
"nature atates" at time interval $t$;

$x_{t-1}$ and $x_{t}=$ vector of parameters to optimize at the beginning and at the end of time interval $t$.

The first statement, the most imple (and the most rough)is to make the dynamic problem a satical one. This is imply enough when the nature tate $y_{s}(s=$ number of nature state) is taken as concrete realisation of vector of random (indefinite) variables for the whole studied peried $T$ :

$$
y_{s}=\left(y_{1 S}, \ldots, y_{t s}, \ldots, y_{T s}\right)
$$


and the possible action of man $x_{i}$ ( $i=$ number of action or variant) is the choice of a ingle-valued trajectory of the syatem development for the whole peried $T$ :

$$
x_{i}=\left(x_{i i}, \ldots, x_{t i}, \ldots, x_{r i}\right) \text {. }
$$

At such a statement of the problem the general sequence of its - Olution can be the same a for the atical problems.Some realination (2) and several possible actions (3) are chosen. This is done by the formal method [3] or heuriatic means.

For each action $x_{i}$ and ature state we estimate the expenditures $3_{\text {is by functional (I). This results in a "pay matrix" }\left\|3_{i s}\right\| \text { on }}$

The shortcoming of this statement are obvious.

The second statement (and all following ones) supposes that the aim of the dynamic problem solution is the choice of an expedient action for the nearest time period ("first tep") only. One of the porsible ways of solving such a problem is [2]as follows:

(a) several possible actions are planned at the first step

$$
x_{i} \equiv x_{i i}
$$

(b) a series of realisation (2) for the whole wtudied period are chosen as before;

(c) for each planned action at the first step and the chosen nature atate determinate optimization calculations are carried out for all steps beginning vith the second one; this gives a pay

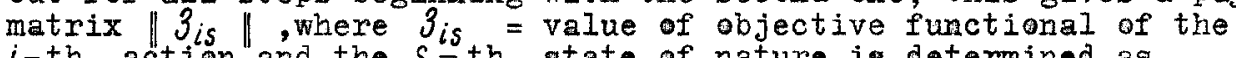
$i-t h$ action and the $S-$ th state of nature is determined as

$$
3_{i s}=3_{1}\left(x_{i}, y_{1 s}\right)+\min _{x_{t}} \sum_{t=2}^{r} 3_{t}\left(x_{t-1}, x_{t}, y_{t s}\right) \text {. }
$$

The first summand in (4) is equal to the functional value in the first interval at fixed $x_{i}$ and $y_{1 s}$; the second summand is an extreme value of the functional at the period of afteraction;

(d) rational actions at the "first step" are chosen on the basis of this matrix using pecial methods and criteria of solutions theary.

The merit of such a statement id the flexible and rather logical adaptation of various actions to different stated of nature.

But it jo laborious and doesn'tquite correspond to the real situations. The "suboptimisation" of system development at the second and following steps at these or those conditions agrees with the assumption that further on (after the first step) we shall precisely know the impending conditions and shall act therefore optimally. In reality, making decisions at the next steps we shall be again under uncertainty and so cannot act optimally.

Taking inte account the second circumstance we may not sometimes demand such a strict "suboptimisation" of system development at the period of "afteraction" and may take a simplified third atatement. Here ome possible actions at the first step and several nature statem (2) for the whole studied period are also planned.

The difference is in the account method of the afteraction period and pay matrix calculation.For each action at the first step geveral (two-five) variants of gyatem development at the period of afteraction are planned (number of these variant are designated by $j$ ):

$$
\left(x_{2 i j}, \ldots, x_{t i j}, \ldots, x_{r i j}\right) \quad j=1,2, \ldots
$$


Further, for all variant of $j$ functional (I) is calculated at each chosen nature tate. These calculations become not eptimization but only "value" (at fixed valuea $x_{t i j}$ ) calculations not as in the abovementioned second atament. Such a calculation determine the expenditure value:

$$
3_{i s j}=3_{1}\left(x_{i}, y_{1 s}\right)+\sum_{t=2}^{r} 3_{t}\left(x_{t-1 i j}, x_{t i j}, y_{t s}\right) \text {. }
$$

Now we suggest taking into account the adaptation of gyom development at the period of afteraction at diverse nature states by the choice of guch a variant (from the mentionad number) for which the expenditures at the given nature atate will be minimal:

$$
3_{i s}=\min _{j} 3_{i s j} \text {. }
$$

This agrees with the assumption that at the second and following step we shall choose this or that variant of the further system development dependent upon the factual conditions, but this circumstance is accounted here in the implified form. The value 3 is obtained by relation (7) are used for filing the pay matrix $\left\|3_{i s}\right\|$. It following analyeis and choice of rational actions is going on in the usual order.

The fourth tatement differs from the above nes followe: each rational action at the first otep (optimal on the corresponaing criterion) is determined at the assumption that at all steps during the afteraction period the choice is implemented by thia criterion. In other words, we choose a certain criterion, for instance that of Wald, and optimize the syatem development for the whole atudied period. optimal action obtained for the first atep belongs to the rational actions. Then we optimize the system development (also for the whole tudied period) by another criterion ( $f$ or example the Savage criterion) and we get one more rational action at the firgt atep, etc.

Having fixed the criterion of optimality $K$ we come to the problem girilar to tochastic dynamic problem (at the known probable description) when the extremum of the mathematical expectation of the functional is searched for. It can be solved uaing ideas and methods of dynamic programing. For instance, if we take the Wald criterion (minimax expenditures) then for each $t$-th time interval the following functional equation must be solved (starting from the end):

$$
\stackrel{0}{K}_{t}^{r}\left(x_{t-1}\right)=\min _{x_{t}} \max _{y_{t}}\left[3_{t}\left(x_{t-1}, x_{t}, y_{t}\right)+\stackrel{\circ}{K}_{t+1}^{r}\left(x_{t}\right)\right] \text {, }
$$

where:

$$
\begin{aligned}
\stackrel{\circ}{K}_{t}^{r}= & \text { minimal posible criterion value for the peried from } \\
& \text { the beginning of the } t-t h \text { interval to the end of } \\
& \text { the tudied peried (it depenas upor the vecter } \\
& \text { value } x_{t-1} \text { ). }
\end{aligned}
$$

The selution of such a problem at the continueug values of vectors $x$ and $y$, enpecially at their great dimengion goes with great (possibly even unsolvable) computational difficulties. But, if a finite and not too large amount of vector values $x_{t}$ is taken,characterising diverse syatem states and al o co limited number of nature states (making the problem discrete), then the solution become practically pogaible. In [3] there is the algorithm of problem solution in such a statement on the base of which the computer program is worked out.

The expedient usage of this or that mentioned statemento depends 
upon the peculiaritie of the problem: It general laboriousnes (accounting for the computersuged), the possible dates and the olution periodicity, etc. For each problem this queation has to be apecified. The second statement is the mest widely uad now.

In [3] there are examples of problem slutions for power systems accounting for the uncertainty of initial information.

\section{Referencen.}

I. Льюс Р.Д., Райе Х. Игры и решения. М., изд-во кностр. лит., I96I.

2. Беляев J.С. Вопросы оптимизации больших систем в вероятносрньх ситуациях. "Экономика и математические методы", т.3,Вып.6, I967. 3. Соорник "Вопросы построения автоматизированных инбориационных систеи управления развитием электроэнергетических спстемй, вып. I. Учет неопределенности исходной инфориации, сэи СО АН СССР, иркутск, 1973. 